\title{
Realidade Aumentada Aplicada ao Ensino e Aprendizagem do Campo Magnético de um Ímã em Forma de Ferradura
}

\author{
Adriana Azeredo de Souza Ribeiro, Instituto Federal Fluminense - IFF \\ adriasribeiro@yahoo.com.br \\ Adriana Barreto de Oliveira Siqueira, Instituto Federal Fluminense - IFF \\ adriana.uenf@hotmail.com \\ Suzana da Hora Macedo, Instituto Federal Fluminense - IFF \\ shmacedo@iff.edu.br
}

\section{Resumo}

Este artigo apresenta uma proposta de ensino e aprendizagem de campo magnético apoiada por objetos de aprendizagem desenvolvidos em ambiente de Realidade Aumentada. Para isso, foi realizado um experimento com um ímã em forma de ferradura, onde foi visualizada a simulação da representação das linhas de campo magnético uniforme em três dimensões usando Realidade Aumentada. Participaram nestes experimentos os alunos do terceiro ano do ensino médio de uma escola pública do Estado. Nos resultados obtidos, através de questionários, verificou-se que os alunos conseguiram visualizar as linhas de campo magnético e obter uma melhor compreensão do conceito físico estudado. Sendo assim, este estudo contribuiu para uma Aprendizagem Significativa e consequentemente, para a melhoria do ensino de Física, trazendo subsídios tanto para professores quanto para alunos.

Palavras-chave: Realidade Aumentada. Ímã em forma de ferradura. Campo magnético. Aprendizagem Significativa.

\section{Augmented Reality Applied to Teaching and Learning Magnetic Field of a Magnet Shaped Horseshoe}

\begin{abstract}
This paper presents an approach to teaching and learning magnetic field supported by learning objects developed in Augmented Reality environment. For this, an experiment was conducted with a horseshoe shaped magnet, where the simulation representation of lines of uniform magnetic field was visualized in three dimensions using Augmented Reality. Participated in these experiments the students of the third year of high school in a public school in the state. The results obtained through questionnaires, it was found that students were able to visualize the simulation of the magnetic field lines and get a better understanding of the physical concept studied. Thus, this study contributed to a Meaningful Learning and consequently to improve the teaching of physics, bringing benefits both for teachers and for students.
\end{abstract}


Keywords: Augmented Reality. Horseshoe-shaped magnet. Magnetic Field. Meaningful learning.

\section{Introdução}

O estudo do eletromagnetismo causou uma verdadeira evolução tecnológica na produção do uso da energia elétrica, em todo o mundo. Antes disso, a maneira de se obter energia era através de pilhas e baterias, que fornecem apenas quantidades relativas de energia. Com a descoberta de que o campo magnético produz corrente elétrica, surgiu um dispositivo chamado gerador, existente em todas as centrais elétricas de todos os países, capaz de fornecer enormes quantidades de energia elétrica, totalmente indispensável no mundo moderno (LUZ e ALVARENGA, 1997, p. 499). A construção de um gerador de energia tem como base um ímã que caracteriza o foco da nossa pesquisa no estudo das linhas de campo magnético.

O estudo das linhas de campo magnético para os alunos da educação básica (ensino médio) é importantíssimo, principalmente para aqueles que querem ingressar nos cursos técnicos, visto que o artigo $36 \S 1^{\circ}$ da Lei de Diretrizes e Bases da Educação (LDB) estabelece que ao final do Ensino Médio o aluno deve ter o domínio dos princípios científicos e tecnológicos que presidem a produção moderna. (BRASIL, 2013).

Na formação básica e técnica, a compreensão dos fenômenos eletromagnéticos é a base científica para o estudo dos geradores, os quais são os fundamentos da conversão da energia mecânica em elétrica e vice-versa. Porém, verifica-se que as dificuldades de aprendizagem dos conteúdos de eletromagnetismo se devem, principalmente, à impossibilidade de visualização dos campos magnéticos por parte dos alunos no espaço tridimensional. Segundo Paz, "Constatamos que as dificuldades de aprendizagem dos conteúdos de eletromagnetismo se concentram no entendimento das interações e comportamento das variáveis eletromagnéticas no espaço tridimensional, [...]" (2007, p. viii). Sendo assim, neste trabalho foi utilizado um Objeto de Aprendizagem (OA) desenvolvidos em Realidade Aumentada (RA) utilizando o software Nyartoolkit como ferramenta de apoio ao ensino e aprendizagem com o objetivo de proporcionar a construção do conceito de campo magnético através da visualização das linhas de campo magnético em três dimensões (3D). Neste objeto, o aluno poderá visualizar as linhas de campo magnético entre os polos do ímã em formato de ferradura.

A Realidade Aumentada é definida pela inserção de objetos virtuais no ambiente físico, mostrada ao usuário, em tempo real, com o apoio de algum dispositivo tecnológico, usando a interface do ambiente real, adaptada para visualizar e manipular os objetos reais e virtuais (KIRNER, 2008, p. 9). No entanto, é a combinação de objetos reais e virtuais. (MILGRAN e KISHINIO, 1994).

Nesta pesquisa foi utilizado um objeto real um ímã em forma de ferradura com as suas respectivas linhas de campo magnético uniforme (mundo virtual). Tal fenômeno não é possível de se ver a olho nu. Normalmente, para fins educativos, nos livros didáticos, o campo magnético é representado em planos bidimensionais, ou seja, traçando um conjunto de linhas na região onde elas existem (figura 1). Nos experimentos, essas linhas podem ser materializadas, colocando-se um ímã em uma superfície lisa e pulverizando delicadamente limalha de ferro bem fina sobre o mesmo, adquirindo assim uma configuração que concretiza as linhas de campo magnético 
uniforme (figura 2). No entanto, o caráter tridimensional é particularmente relevante no entendimento do conceito.

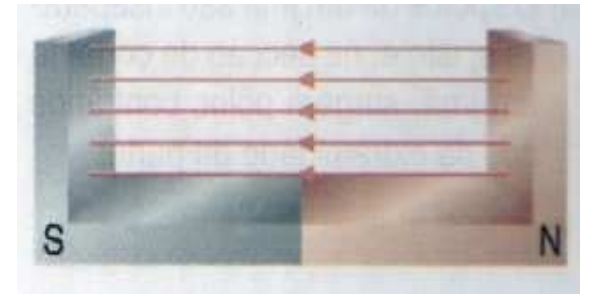

Figura 1: Representação das linhas imaginárias de campo magnético de um ímã em forma de ferradura.

Fonte: Info Escola Navegando e Aprendendo da http://www.infoescola.com/fisica/ima/

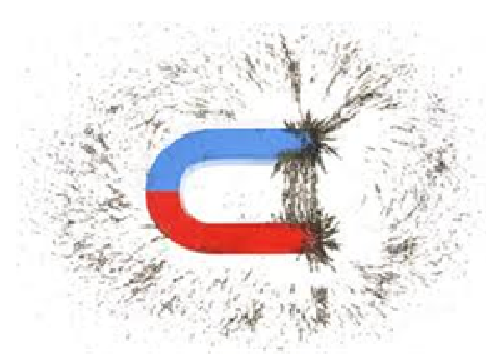

Figura 2: Representação das linhas de campo magnético de um ímã com limalha de ferro em forma de ferradura.

Fonte: Info Escola Navegando e Aprendendo da http://www.infoescola.com/fisica/ima/

A evolução da tecnologia tem colaborado para o avanço da educação, fazendo com que as aulas se tornem mais interativas e dinâmicas, substituindo as aulas meramente tradicionais, com uso de quadro e giz.

Com a criação de novas ferramentas, sistemas, portais e aplicativos para utilização em diversos aparelhos, a educação tem alcançado um novo patamar, em que ensinar torna-se tão divertido e prazeroso quanto aprender. (LOPES, 2013, p. 46).

A utilização da informática no cotidiano escolar é uma realidade na maioria das escolas. E vem contribuindo positivamente para o desenvolvimento cognitivo e intelectual dos alunos, através de novas experiências e vivências virtuais, em lugares, tempos, espaços, onde e quando as coisas acontecem, oferecendo um ensino de melhor qualidade aos alunos e melhores formas de auxílio ao professor nesse processo da construção do conhecimento. De acordo com Lemos e Carvalho, o software educativo “...pode ser a interface entre os professores e os estudantes como uma ferramenta auxiliar para melhorar o processo de ensino e de aprendizagem de um conteúdo ou assunto educacional..." (2010, p. 2). E segundo Wiley, Objeto de Aprendizagem (OA) é qualquer recurso digital que pode ser reutilizado para apoiar a aprendizagem (WILEY, 2000).

Assim, com (OA) o aluno poderá visualizar a interação do campo magnético uniforme e interagir com o mesmo, como nunca experimentado anteriormente, levando o aluno ao despertar para novos conhecimentos com o apoio da Realidade Aumentada.

Para o uso da RA são necessários alguns requisitos básicos como: um computador, uma webcam, um programa desenvolvido com uma biblioteca de programação e uma placa de papel com um símbolo no interior, denominado marcador fiducial. Este marcador é colocado em um objeto no qual se deseja que ocorra a interação. Ao ser visualizado pela câmera do computador, o marcador deve ser reconhecido e levará a uma biblioteca de programação pré-estabelecida. Aparecerá, então, na tela do computador, o primeiro objeto em que estava o marcador, juntamente com o objeto que estará na biblioteca. Os dois objetos serão fundidos em um mundo misto que misturará o mundo real com o mundo virtual (MACEDO; BIAZUS; FERNANDES, 2011, p. 158).

Para a criação do ambiente em (R A) do Objeto de Aprendizagem foi utilizado o Nyartoolkit baseado no Artoolkit e funciona em qualquer dispositivo Android, sistema operacional de código aberto baseado em Java (MULLEN, 2011). Com isso, foi 
utilizado um objeto real, um ímã em forma de ferradura (figura 3), e o marcador para o respectivo objeto (figura 4).

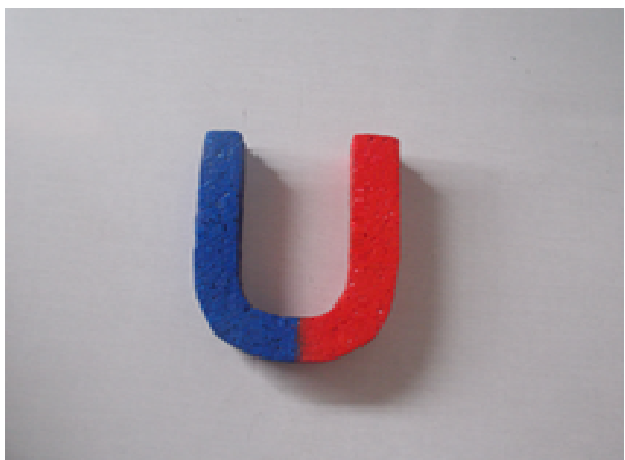

Figura 3: Modelo de um ímã em forma de ferradura utilizado no experimento.

Fonte: Autoras.

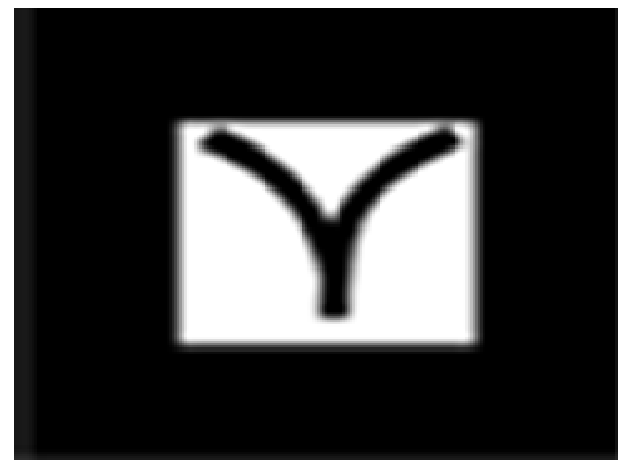

Figura 4: Marcador utilizado no experimento do ímã em forma de ferradura. Fonte: Autoras.

$\mathrm{Na}$ figura 5, temos o exemplo de Realidade Aumentada do Objeto de Aprendizagem, em que marcador foi posicionado de forma que a câmera capturasse a imagem. Então, após o registro da imagem, esta fundiu-se às linhas de campo magnético uniforme que estavam armazenadas na biblioteca pré-estabelecida. A usuária, o ímã e as linhas de campo magnético uniforme encontram-se agora em um ambiente de (RA).

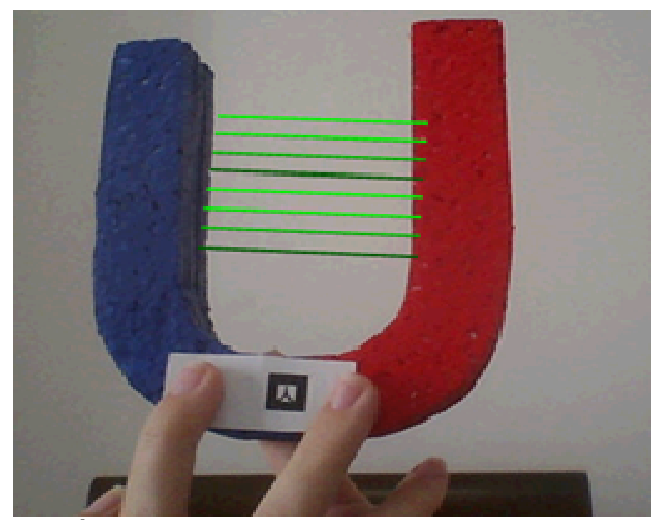

Figura 5: Ímã e as linhas de campo magnético uniforme.

Fonte: Autoras.

\section{Aprendizagem Significativa}

A partir dos conhecimentos prévios dos alunos sobre o conceito de campo magnético, apresentou-se uma proposta de ensino, inspirada na teoria da Aprendizagem Significativa, de David Ausubel, utilizando o recurso de Realidade Aumentada.

Moreira (2006, p. 13-14) apresentando uma visão geral da teoria da Aprendizagem Significativa, afirma que, para Ausubel, a aprendizagem, tal como ela ocorre na sala de aula, é muito influenciada por aquilo que o aluno já sabe. Nesta perspectiva, Aprendizagem Significativa, é o processo por meio do qual uma nova informação relaciona-se com um aspecto relevante da estrutura de conhecimento do indivíduo e ocorre quando a nova informação ancora-se em conceitos ou proposições 
relevantes pré-existentes na estrutura cognitiva do indivíduo. Esta estrutura é definida por Ausubel como elemento subsunçor. Os conceitos intuitivos de força e campo já existem na estrutura cognitiva do aluno, eles servirão de subsunçores para as novas informações sobre certos tipos de força e campo. No entanto, o processo de ancoragem da nova informação resulta em crescimento e modificação do subsunçor. Os subsunçores existentes na estrutura cognitiva do aluno podem ser abrangentes e bem desenvolvidos ou limitados e pouco desenvolvidos.

Em contraste com a Aprendizagem Significativa, Ausubel menciona que a aprendizagem mecânica ou automática ocorre até que alguns conhecimentos relevantes às novas informações da mesma área existam na estrutura cognitiva e possam servir de facilitadores, ainda que pouco trabalhados. À medida que a aprendizagem começa a ser significativa, esses facilitadores vão sendo assimilados, tornando-se, pois, mais capazes de facilitar ou ancorar a nova informação (MOREIRA, 2006, p. 15-17).

\section{Metodologia}

Inicialmente, foi realizado um pré-teste para a verificação dos conhecimentos prévios dos alunos em relação ao tema a ser estudado, através de questionários. Em seguida foi ministrada uma aula sobre campo magnético e como surgem as linhas de campo magnético. Logo após foi utilizado o objeto de aprendizagem em Realidade Aumentada (figura 6). Neste objeto pode-se visualizar a simulação da representação das linhas de campo magnético uniforme no interior do ímã em forma de ferradura.

O objetivo deste experimento foi criar um ambiente lúdico em sala de aula, onde o aluno pudesse interagir e também visualizar de forma pictórica as linhas de campo magnético que antes não era possível ver a olho nu. De acordo com Mouly um indivíduo tem necessidades que precisam ser satisfeitas; ao professor cabe fazer com que obtenham satisfação destas necessidades (1966). Contudo, com a Realidade Aumentada o aluno pode visualizar a simulação da representação das linhas de campo magnético em três dimensões, tornando o processo de ensino e aprendizagem e as aulas mais divertidas e prazerosas.

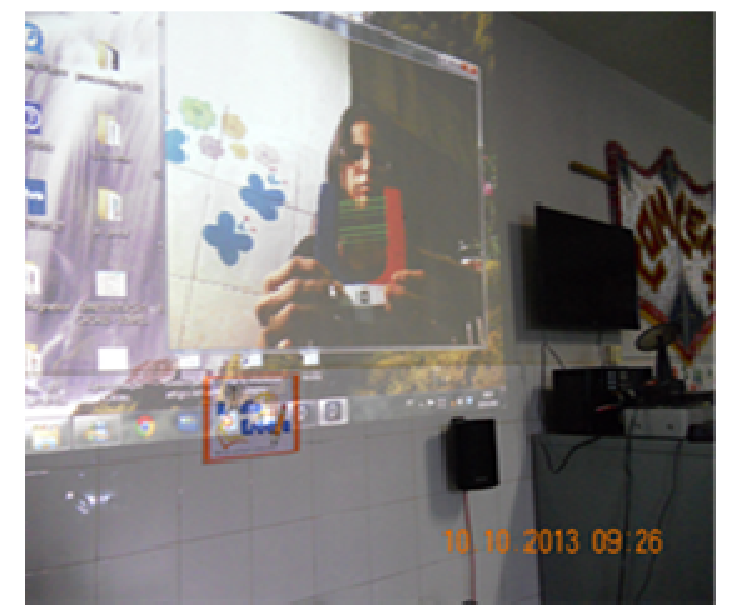

Figura 6: Usuária com o ímã e o seu campo magnético uniforme em ambiente de Realidade Aumentada. Fonte: Autoras.

Após os alunos interagirem com Objeto de Aprendizagem foi aplicado 
novamente o pré-teste sobre o campo magnético e em seguida um teste sobre o uso do recurso tecnológico Realidade Aumentada no estudo do campo magnético. Foi também preenchido um termo de ciência e concordância autorizando suas participações na realização desta pesquisa. Os testes foram aplicados à turma do terceiro ano do ensino médio do turno diurno, da Escola Estadual Doutor Phillippe Uébe - Guarus - Campos RJ, totalizando 22 alunos entre 17 e 21 anos, onde os resultados são descritos na próxima seção.

\section{Resultados e discussão}

Após a conclusão do experimento foram levantados os resultados dos questionários. $\mathrm{O}$ primeiro pré-teste que foi aplicado antes da aula mostrou que 36\% dos alunos não sabiam o que é um campo magnético e $28 \%$ pouco

sabem. No entanto, $50 \%$ já ouviu falar em campo magnético pelo professor. Mas a maior parte (90\%) não sabe como surgem as linhas de campo magnético e 64\% não viu a representação das linhas de campo magnético.

O gráfico 1 mostra os resultados deste primeiro pré-teste:

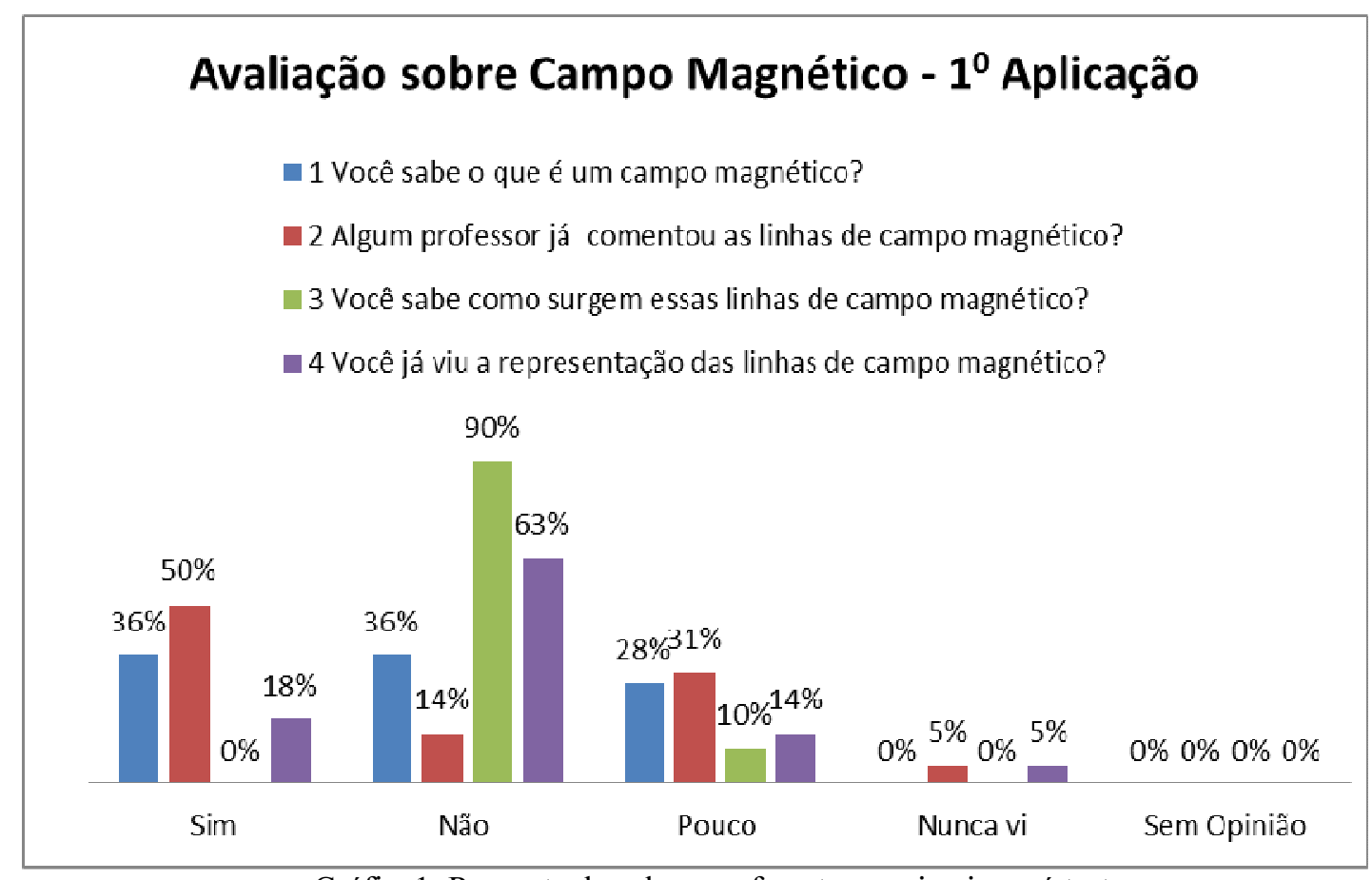

Gráfico1: Resposta dos alunos referente ao primeiro pré-teste.

Foram feitas questões em que os alunos deveriam ilustrar as linhas de campo magnético em um ímã em forma de ferradura. No entanto, os alunos fizeram a figura, porém não as linhas de campo magnético uniforme. Na verdade, ilustraram a representação de cargas elétricas. Esse mesmo questionário foi aplicado pela segunda vez após a aula sobre campo magnético. Verificou-se que todos os alunos responderam afirmativamente que sabem o que é um campo magnético. No entanto, $14 \%$ dos alunos não sabem ou pouco sabem como surgem as linhas de campo magnético.

O gráfico 2 mostra os resultados deste segundo pré-teste: 


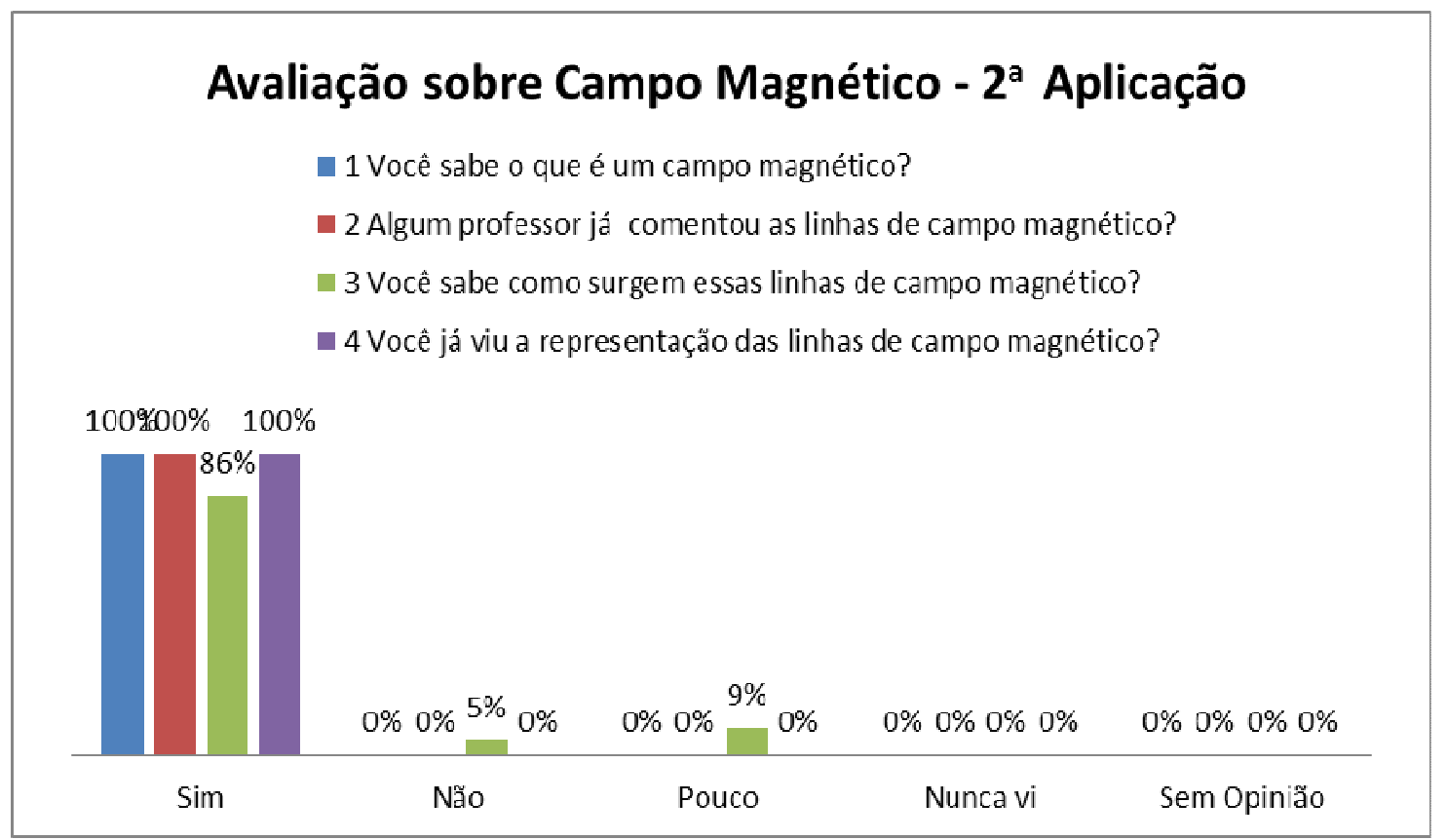

Gráfico2: Resposta dos alunos referente ao segundo pré-teste.

Quanto às questões em que os alunos deveriam ilustrar as linhas de campo magnético em um ímã em forma de ferradura, verificou-se que $86 \%$ dos alunos conseguiram ilustrar corretamente as linhas de campo magnético uniforme. No terceiro momento aplicou-se um questionário sobre o uso do recurso tecnológico Realidade Aumentada em que chegou-se a conclusão de que os alunos concordam com a utilização desta ferramenta como apoio ao ensino dos conceitos de campo magnético e até mesmo de outros tópicos.

Os gráficos 3 e 4 mostram os resultados deste teste:

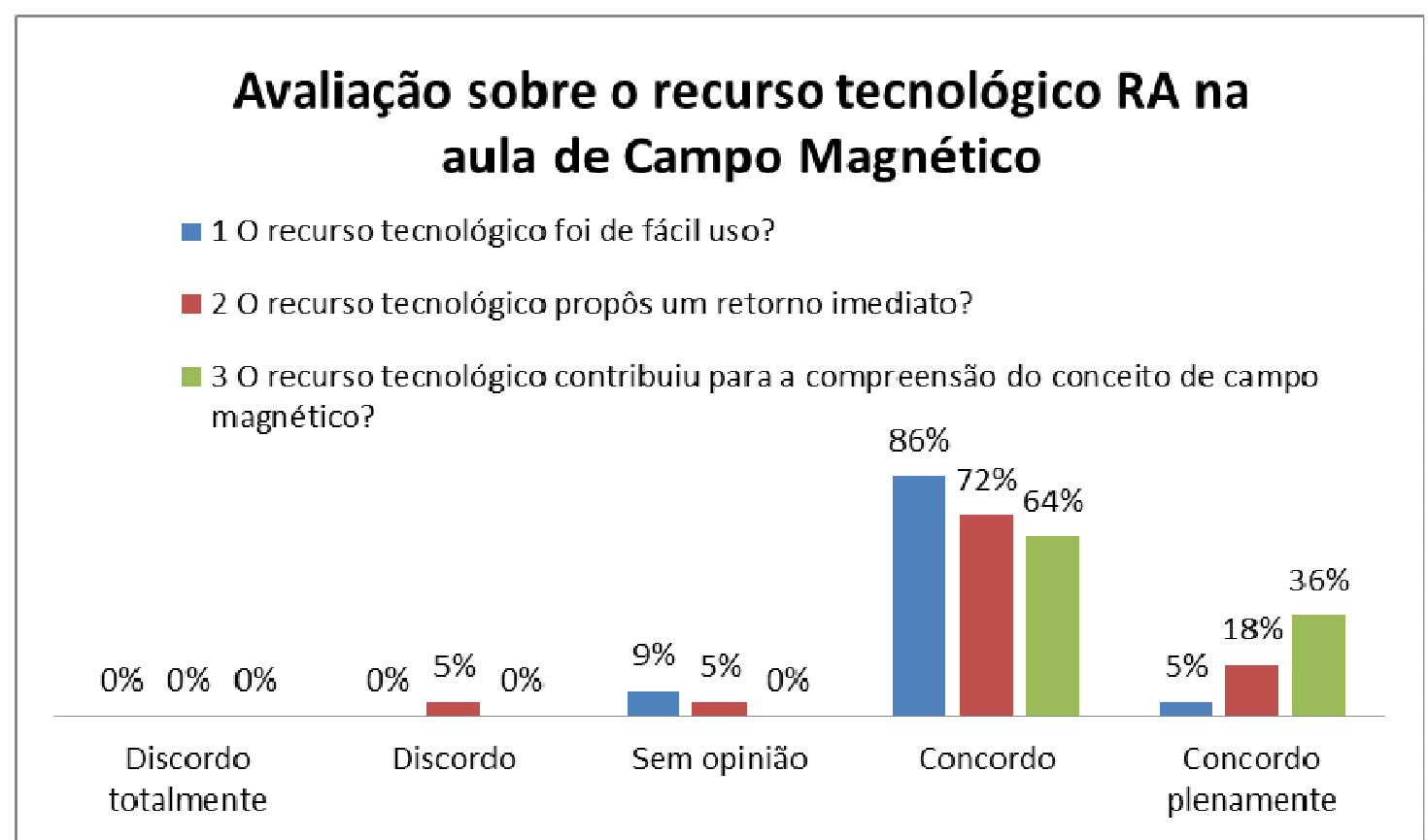

Gráfico 3: Respostas dos alunos referente questionário sobre o recurso tecnológico RA. 


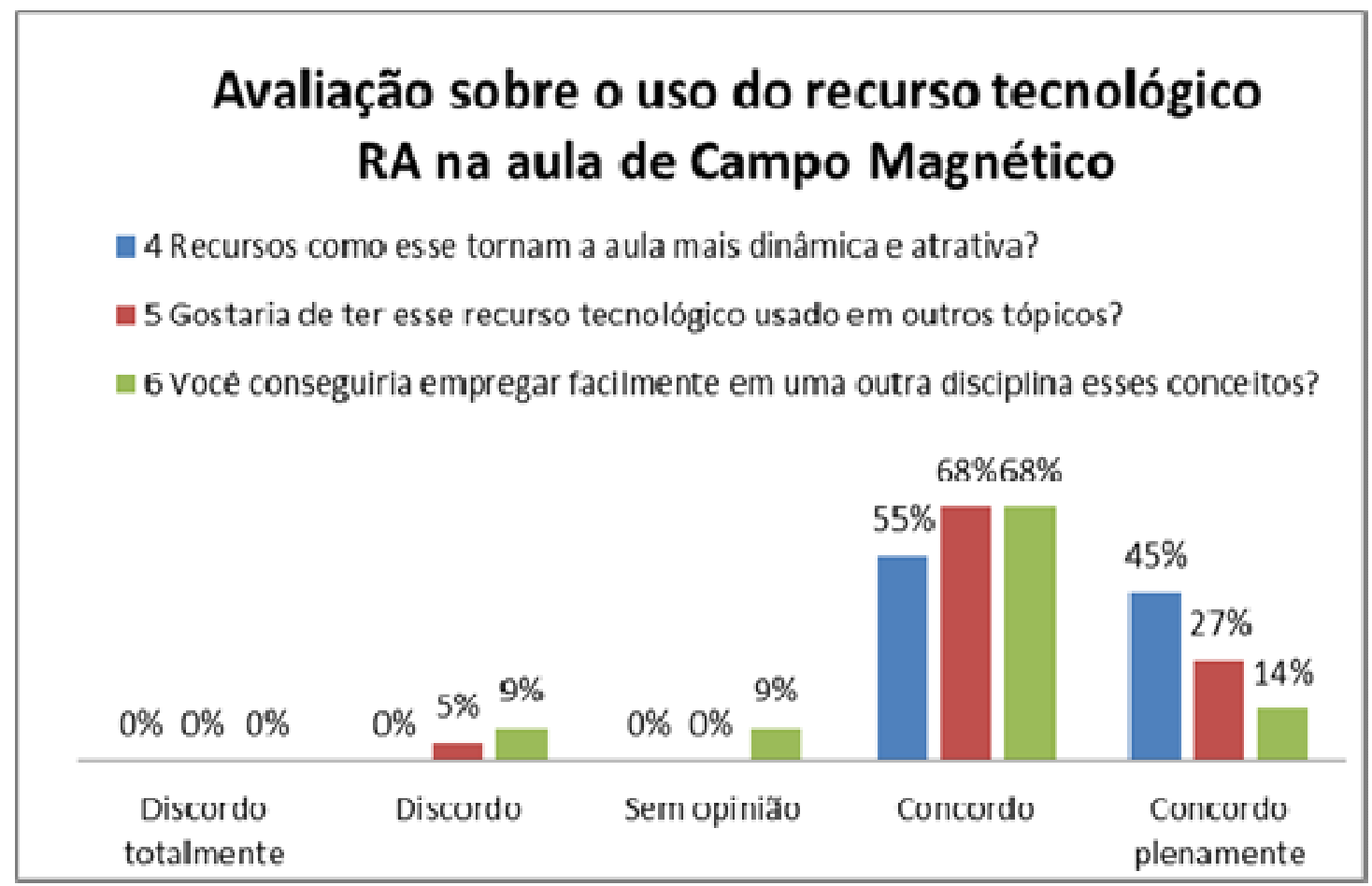

Gráfico 4: Respostas dos alunos referente questionário sobre o recurso tecnológico RA.

Com relação à pergunta 1 a respeito do recurso tecnológico se foi de fácil uso, $86 \%$ dos alunos concordam. E na pergunta 2 se o recurso tecnológico propôs um retorno imediato, $72 \%$ concordaram. E na pergunta 3 , se o recurso tecnológico contribuiu para a compreensão do conceito de campo magnético, 64\% concordaram. Na pergunta 4, se os recursos como esse tornam a aula mais dinâmica $55 \%$. Na pergunta 5 se gostaria de ter esse recurso tecnológico usado em outros tópicos $68 \%$ e na pergunta 6 se ele conseguiria empregar facilmente em uma outra disciplina esses conceitos, também $68 \%$.

Foram feitas perguntas sobre o que eles acharam da experiência e do projeto, em que os alunos puderam responder livremente às questões. A seguir serão destacadas as principais respostas:

A - 17 anos. Muito interessante! Ajudou a entender uma coisa que eu nunca tinha visto.

B- 17 anos. Muito legal! Por que na teoria eu não consigo entender, mas vendo na prática fica mais fácil de compreender.

C - 17 anos. Muito boa! Esse tipo de experiência torna o entendimento muito mais fácil e interativo do que numa aula comum.

D - 17 anos. Boa! Pois dinamicamente ajuda na compreensão do assunto.

F - 18 anos. Esta experiência me esclareceu muitas dúvidas e me fez adquirir mais conhecimentos.

\section{Conclusão}

Nesta pesquisa verificou-se que o uso do recurso tecnológico Realidade Aumentada possibilitou aos alunos a visualização das linhas de campo magnético uniforme em um ímã em forma de ferradura. Antes do experimento os alunos não sabiam como surgiam essas linhas de campo magnético. 
Os resultados mostram-se satisfatórios, pois revelam que houve melhora significativa no aprendizado do conceito do campo magnético além de tornar a aula mais atrativa e dinâmica conquistando a atenção dos alunos.

O ambiente em Realidade Aumentada contribuiu para a criação de um ambiente lúdico em sala de aula, onde o aluno pode interagir com o Objeto de Aprendizagem levando a uma motivação com a visualização em três dimensões das linhas de campo magnético uniforme. E segundo as perguntas livres dos questionários estes experimentos ajudaram a entender o fenômeno que nunca tinham visto, esclareceu dúvidas, adquiriram mais conhecimentos e todos gostariam de ter esse recurso tecnológico em outras aulas.

Esta experiência pode ser realizada várias vezes pela sua simplicidade e utilização de equipamentos básicos como: uma webcan, um laptop e se possível um datashow com um telão para que todos no mesmo momento consigam visualizar as linhas de campo magnético uniforme.

Com os resultados obtidos dos questionários, verifica-se que a Realidade Aumentada contribuiu no processo de ensino e aprendizagem, de acordo com Teoria da Aprendizagem Significativa.

\section{Referências}

BRASIL. Ministério da Educação. Secretaria de Educação Média e Tecnológica. Lei de Diretrizes e Bases da Educação. Brasília: MEC/SEMTEC, 2013.

KIRNER, C. Definições. In: SISCOUTO, R; COSTA, R. (orgs.). Realidade virtual e aumentada: uma abordagem tecnológica, 2008. Disponível em: <http://www.ckirner. com/download/livros/RVA08-Livro.zip>. Acesso em: 20 agosto. 2013.

LEMOS, B. M., CARVAlHO, C. V. Uso da Realidade Aumentada para Apoio ao Entendimento da Relação de Euler. RENOTE. In: Revista Novas Tecnologias na Educação. V. 8, p. 1-10, 2010.

LUZ, A. M. R.; ALVARENGA, B. Física: volume único. São Paulo: Scipione, 1997.

LOPES, J. A Colaboração da Tecnologia para a Educação. n. 182, Ano 16, p. 46, maio 2013.

MACEDO, S. H.; BIAZUS, M. C. V.; FERNANDES, F. A. Ensino do campo magnético de um ímã em forma de barra utilizando recursos de realidade aumentada. Informática na Educação: teoria e prática, Porto Alegre, v. 14, n. 1, p. 158, jan./jun. 2011.

MOREIRA, M. A. A teoria da Aprendizagem Significativa e sua implementação em sala de Aula. São Paulo: UnB, 2006.

MILGRAM, P.; KISHINO, F. A Taxonomy of Mixed Reality Visual Displays, 1994. Disponível em: <http://etclab.mie.utoronto.ca/people/paul_dir/IEICE94/ieice.html $>$. Acesso em: 24/07/2010. 
MOULY, J. G. Psicologia Educacional, 1 ed. São Paulo: Livraria Pioneira Editora, 1966.

MUlLEN, T. Prototyping Agumented Reality. Copyright (C) 2011 por John Wiley \& Sons, Inc., Indianapolis, Indiana, Publicado simultaneamente no Canad.

PAZ, A. M. Atividades Experimentais e Informatizadas: Contribuições para o Ensino de Eletromagnetismo (2007), Universidade Federal de Santa Catarina, Florianópolis, 228 p. Tese de Doutorado.

WILEY, D. A. (2000). Connecting learning objects to instructional design theory: A definition, a metaphor, and a taxonomy. In D. A. Wiley (Ed.), The Instructional Use of Learning Objects: Online Version. Retrieved MONTH DAY, YEAR, from the World WideWeb:http://reusability.org/read/chapters/wiley.doc. 